\title{
A TORRE DAS CIÊNCIAS
}

\author{
Raquel Gonçalves Maia* \\ Departamento de Química e Bioquímica, Faculdade de Ciências da Universidade de Lisboa \\ rmcgonc@gmail.com
}

\begin{abstract}
A Torre das Ciências existe mesmo; e está em permanente construção. Não, não é uma Torre de Babel - o céu há muito que foi atingido... Não é cónica, não é cilíndrica, nem tem uma qualquer forma regular. Não tem por base uma ciência, nem por patamares outras. Espraia as ciências formais, dilui as margens das ciências físicas e das ciências da vida, abraça laivos das ciências sociais, da filosofia e da história das ciências, gera ciências aplicadas... O conhecimento científico não pode ser uma Torre de Marfim. Há um propósito real nas ciências: a construção de uma atmosfera propícia à difusão do conhecimento que elimine erros conceptuais graves e permita aos alunos, e ao público em geral, usufruir de um processo de educação com qualidade. Afinal, às ciências se deve a maior modificação das condições de vida humana nos últimos séculos. E a Química onde está?

Há "centralidade” na Química. São vários os mapas de ciência que o afirmam. Assim o comprova o Mapa de Consenso, em termos da intermediação da Química entre disciplinas científicas, da sua preponderância na emergência e desenvolvimento de ciências interdisciplinares e, consequentemente, nos requisitos exigidos pelos currículos de cursos universitários.
\end{abstract}

\section{INTRODUÇÃO}

Segundo a Bíblia, há muitos séculos, homens houve que construíram uma enorme torre com a intenção de atingirem os céus e entrarem nos domínios de Deus. Chamou-se - todos o sabem - Torre de Babel. Babel significa numa eventual língua semítica “o portão de Deus”. Mas, simbolicamente, a palavra Babel é ainda mais rica, traduz a "confusão". A falta de equilíbrio, a presunção, arrasta o homem para o caos, impede a existência de consensos, cada um diz o que o outro não entende. Esta é uma história muito antiga da humanidade, mas dir-se-ia fabricada nos dias de hoje. A Torre de Babel existe mesmo e, infelizmente, está em permanente construção...

No século XIX surgiu uma escola de pensamento que se designa por "cienticismo" ou "cientismo", muitas vezes identificada com "religião dos cépticos" ou "religião da Ciência”. Os cienticistas praticam uma visão científica absoluta do mundo; segundo eles, a ciência explica a totalidade dos fenómenos do universo. Os cienticistas sofrem do mesmo pecado que os homens que tentaram construir a Torre de Babel, creditam à ciência uma abrangência injustificada, sem fronteiras, sem espaço para a Metafísica e para a Teologia. Mas nem tudo é mau. A verdade é que também não deixam espaço para especulações sobrenaturais e paranormais, dificultando o trabalho de magos, bruxas e adivinhadores do futuro.

A atitude metodológica que tende a considerar o método experimental e a análise quantitativa como a metodologia de maior aproximação à verdade é a base das ciências formais e das ciências naturais. A ciência tem por base a

* Professora Catedrática aposentada razão, mas esta é marcada por condicionantes temporais, culturais e espaciais.

Antes de continuarmos vale a pena clarificar que incluímos: (i) a Matemática e a Computação nas "ciências formais"; (ii) a Física, a Química e a Astronomia nas "ciências físicas"; (iii) a Biologia, a Bioquímica e genericamente todas as ciências começadas por "bio", "zoo”, “eco”, "neuro" e "imuno" nas "ciências da vida"; (iv) todas as ciências que estudam a natureza física do Universo, seja o homem como parte integrante deste, seja o seu meio envolvente, (ii) e (iii), nas "ciências naturais"; (v) a Medicina e as Engenharias nas "ciências aplicadas"; (vii) a Antropologia, a Arqueologia, a Economia e as Ciências Políticas nas "ciências sociais"; (viii) a Filosofia e, genericamente, as Artes e as Letras, nas "humanidades".

\section{A Torre das InfluênCIAS Felizes}

Auguste Comte (1798-1857) e o Positivismo estabeleceram que a ciência era uma composição de domínios de fronteiras fixas; e mais estabeleceram: que havia uma hierarquia nas ciências, classificadas estas desde a base - as Ciências Sociais - até ao topo - a Matemática (Figura 1).

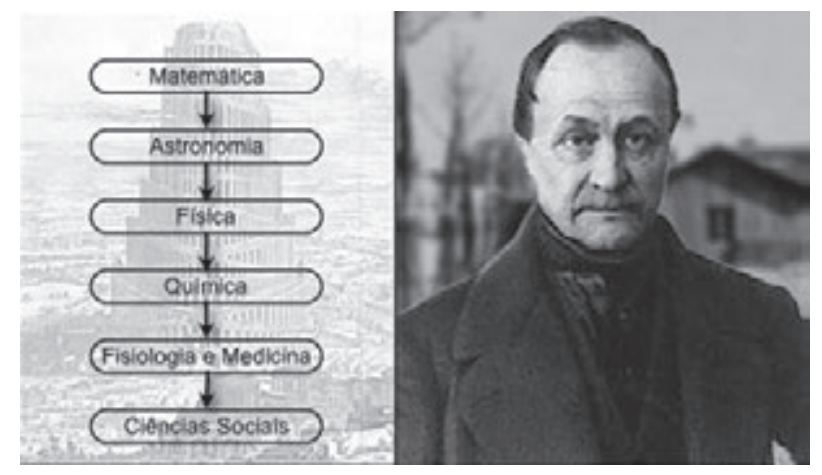

Figura 1 - A “Torre das Ciências” de Auguste Comte 
A Matemática, ocupando o topo, estava mesmo a tocar o portão dos céus... Uma torre vertical, sim, sem ponta de ramificação e na estranha opinião de Comte, concluída. Salvo raras e pequenas excepções, a ciência era, a seu ver, um saber terminado. Muito provavelmente a "higiene cerebral" a que Comte se auto impôs - e que lhe travou o acesso a toda a espécie de literatura nova após ter completado trinta anos - tê-lo-á cegado em relação à dinâmica científica tão florescente no século XIX [1,2]. Era o determinismo universal, puro e duro, com uma lógica de saberes confinados a compartimentos estanques...

Em 1939, o genial John Desmond Bernal (1901-1971), o Sage, pioneiro da cristalografia de raios $\mathrm{X}$ aplicada ao estudo da estrutura de moléculas bioorgânicas, num trabalho, igualmente pioneiro de sociologia das ciências, apresentou um intrincado mapa com uma estrutura algo hierarquizada das ciências (a Matemática foi omitida neste estudo) segundo dois eixos: um eixo vertical determinava dois domínios de investigação, as ciências fundamentais e as ciências aplicadas, estando estas dependentes daquelas; um eixo horizontal definia um primeiro sector, o das ciências físicas, seguido do sector das ciências biológicas e, finalmente, do das ciências sociais (Figura 2). Cerca de 50\% do mapa fica coberto pelas ciências físicas e suas aplicações, mostrando bem a clara dominância que o autor lhes atribuiu $[3,4]$.

Depois do mapa das ciências de Bernal, outros mapas se sucederam e, por muito objectivos que pretendam ser, sempre acabam revelando alguma subjectividade relativa à prática do seu autor; e do seu leitor... Não querendo ser excepção à regra, a nossa apresentação seguinte recaiu sobre o trabalho exposto pelos cientistas Alexandru Balaban e Douglas Klein, em 2006, num artigo cujo subtítulo é "How are different sciences related?”. Trata-se de um esquema de ordenação das ciências, necessariamente parcial, com um significativo grau de hierarquização e de ramificação [5]. Na Figura 3, não incluímos as disciplinas dentro de um casulo e só aparentemente é que o mapa é bidimensional.

Posteriormente, Richard Klavans e Kevin W. Boyack, em 2009, publicaram um interessante estudo de "consenso"

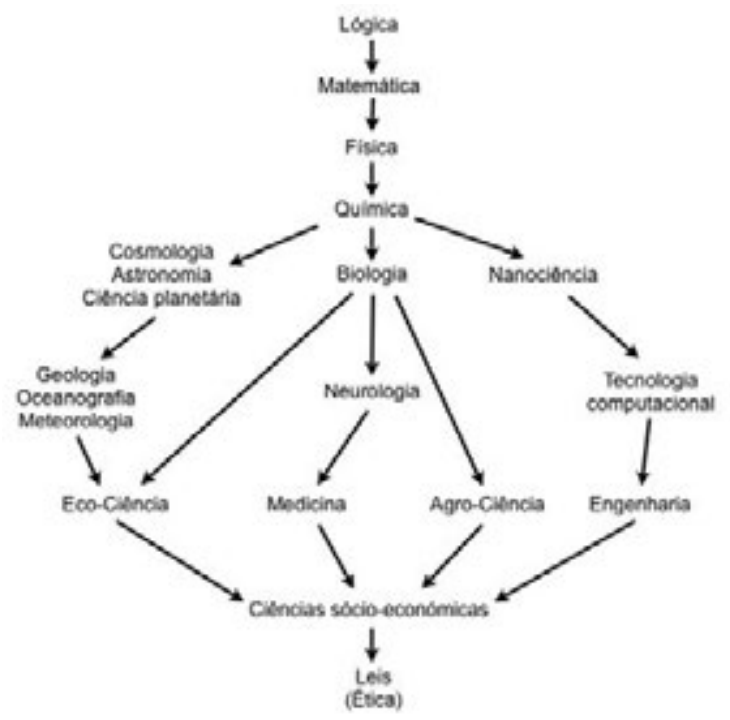

Figura 3 - Diagrama das Ciências de Balaban e Klein

baseado na análise de uma vintena de propostas de mapas de ciência existentes, uns declaradamente lineares, outros cêntricos e outros não-cêntricos [6]. Os autores preferem falar em "consenso" ao invés de convergência, uma vez que a procura de uma solução comum (em termos de forma, conteúdo e interligações) seria muito difícil se não impossível $[7,8]$. Optaram, então, por utilizar um padrão menos elevado, segundo o qual agregam resultados de vários mapas individuais desde que partilhem um largo conjunto de características em comum. Tal agrupamento gerou 16 áreas científicas, assim designadas por ordem alfabética: Biologia (B), Bioquímica (Bi), Ciência Computacional (CC), Ciências Sociais (CS), Doenças Infecciosas (DI), Engenharia (E), Especialidades Médicas (EM), Física (F), Geociências (G), Humanidades (H), Matemática (M), Neurociência (N), Psicologia/Psiquiatria (PP), Química (Q), Química Física (QF), Serviços de Saúde (SS).

A título de exemplo, o caso que atrás referimos ficou disposto como se vê na Figura 3. Verifica-se que a maioria das ciências proposta inicialmente fica codificada por uma única área científica. No entanto, ocorrem por vezes situações que são descritas por mais do que uma área; a Medicina,

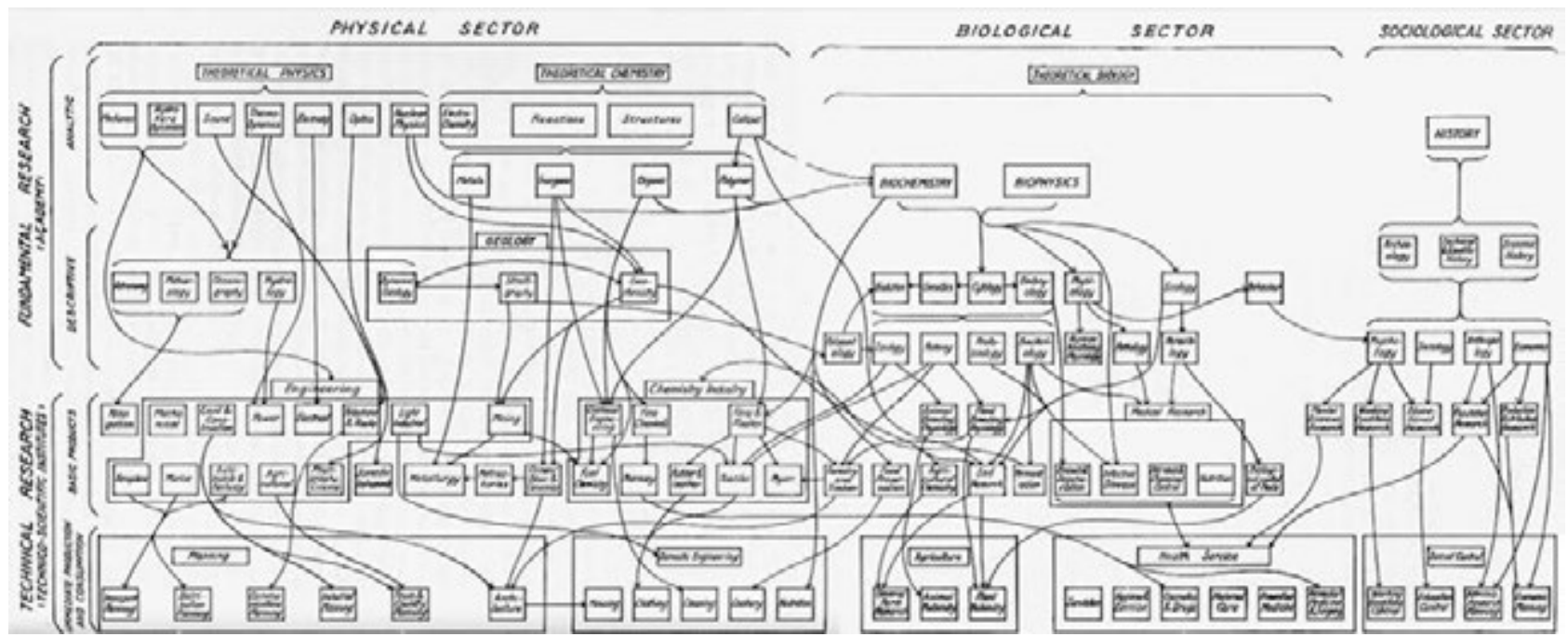

Figura 2 - Diagrama das Ciências de John Desmond Bernal 
por exemplo, reflecte SS, DI e EM e, pelo contrário, a Cosmologia, a Astronomia, a Ciência planetária, a Geologia, a Oceanografia, a Meteorologia e a Eco-Ciência traduzem-se exclusivamente por $\mathrm{G}$.

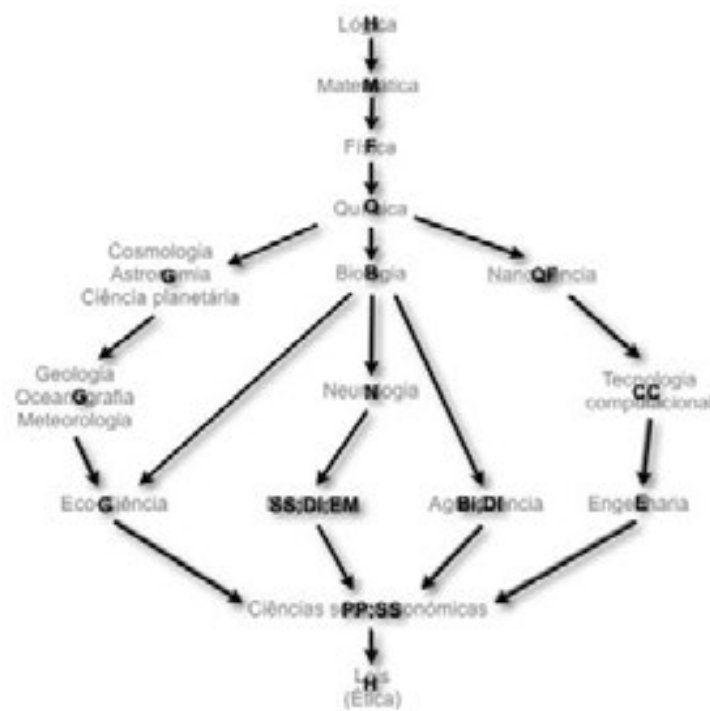

Figura 4 - Diagrama das Ciências de Balaban e Klein, de acordo com a codificação de Klavans e Boyack

De uma forma simplificada, o melhor mapa de consenso da estrutura básica da ciência a que Richard Klavans e Kevin W. Boyack chegaram pode descrever-se de uma forma circular, não cêntrica, como se mostra na Figura 5. A Matemática foi arbitrariamente colocada no topo e, a partir dela, as áreas científicas convencionais correlacionadas dispostas como se num mostrador de relógio. Para o interior deste círculo surgem áreas de maior interdisciplinaridade. A percentagem traduzida pela espessura do traço - uma ligação de consenso que é necessariamente uma ligação importante - refere-se à ocorrência na totalidade dos mapas examinados. O número de ligações que partem de uma área indica, grosso modo, o grau de influência dessa mesma área na ciência em geral, que será tanto maior quanto mais densa for a ligação de consenso; não deve, porém, permitir em qualquer circunstância, implicar que uma dada área é superior a outra.

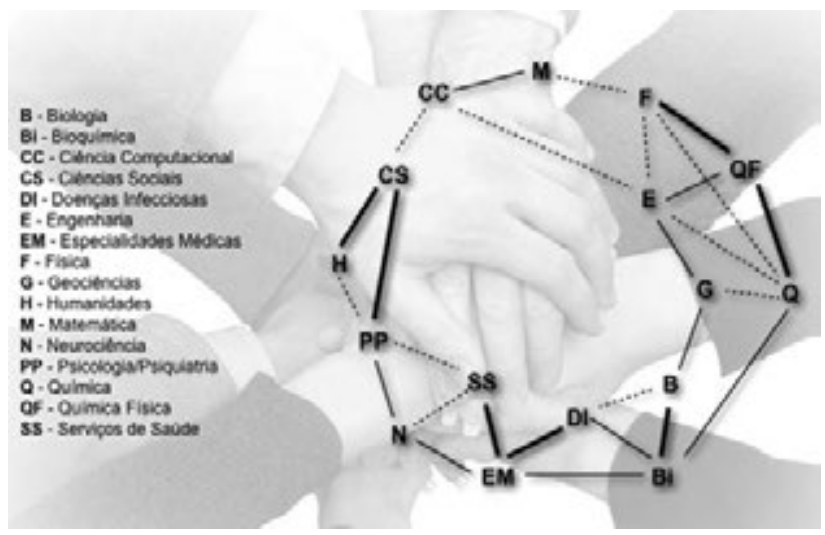

Figura 5 - Mapa de Consenso de Klavans e Boyack

Mas, afinal, para que serve um mapa de ciência? Para começar serve para visualizar aquilo que, de algum modo, já parcialmente conhecemos ou intuímos - as relações entre diferentes áreas da ciência - o que não é objectivo menor. Mas vai mais longe, uma vez que permite (i) uma compreensão básica de como a ciência está organizada, (ii) identificar os nós fundamentais de interdisciplinaridade ou (iii) apontar orientações de investigação. A combinação e ligação de áreas científicas tem tido como resultado a criação de novas disciplinas, como sejam a bioinformática e as nanotecnologias. Sem ser radical, pode afirmar-se que as novas disciplinas (e as grandes descobertas) nascem nas zonas "em branco", isto é, no interior da circunferência gerada no mapa circular pelas "velhas" disciplinas, e localizadas de modo a reflectirem a influência destas. É a “Torre das Influências Felizes” [9].

A importância da ciência na sociedade ganha uma evidência superior e fornece uma estrutura cognitiva para a discussão de questões de política científica, com a sua consequente utilidade a nível do ensino básico, secundário e mesmo superior.

\section{E A QuÍMICA ONDE ESTÁ?}

Se entendermos que uma torre, independentemente do seu formato - linear ou circular, cêntrica ou não-cêntrica - é um mito ascensional, então a Torre das Ciências existe, uma vez que os seus tijolos contam uma história de elevação do conhecimento humano. Não se confunda a linguagem, não se pretenda os céus, deseje-se sim uma investigação e uma educação que enriqueça e eleve a nossa vivência terrena, alicerçada num pensamento crítico, ético e objectivo dos factos e dos fenómenos. Na Torre das Ciências espraiam-se as ciências formais, diluem-se as margens das ciências físicas e das ciências da vida, abraçam-se laivos das ciências sociais, da filosofia e da história das ciências, geram-se ciências aplicadas... É um puzzle multidimensional intricado, curioso, desafiador de disciplinas; mas, vertical; vertical, porque auto-corrector.

O conhecimento científico não é, ou não pode ser, uma Torre de Marfim, torre muitas vezes confundida com o mundo académico universitário [10]. Tem de haver um propósito real nas ciências: a construção de uma atmosfera propícia à difusão do conhecimento que elimine erros conceptuais graves e permita aos alunos, e ao público em geral, usufruir de um processo de educação com qualidade. Afinal, é à ciência que se deve a maior modificação das condições de vida humana nos últimos séculos. E a Química onde está?

O artigo de Alexandru Balaban e Douglas Klein onde é apresentado o diagrama da Figura 3 tem por título "Is chemistry The Central Science?”. A denotação nasce do livro de texto de Química de Theodore Brown e colaboradores [11], mas a designação emerge agora apoiada na interligação entre disciplinas científicas, na emergência e desenvolvimento de ciências interdisciplinares e nos requisitos exigidos pelos currículos de cursos universitários. Se observarmos o diagrama proposto por aqueles autores, podemos constatar a "centralidade” da Química, em termos da frondosa ramificação que ela introduz no tronco comum... Alexandru Balaban é engenheiro químico e os seus projectos de investigação desenvolvem-se no âmbito da Química Orgânica; por seu lado, Douglas Klein é professor de Oce- 


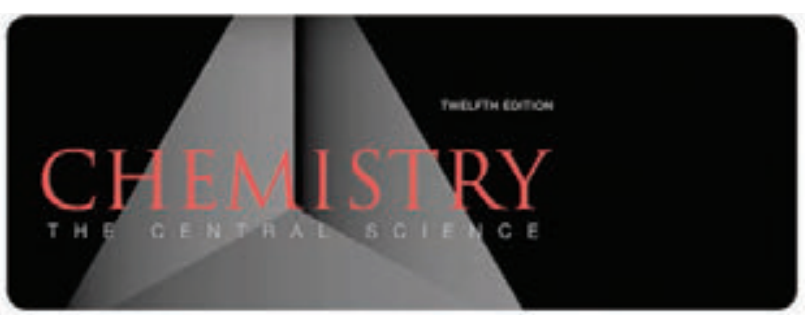

Figura 6 - Pormenor da capa do livro "Chemistry: The Central Science", de Brown et al, 2012 [11]

anografia e as suas pesquisas debruçam-se pela Química e Física Teóricas. O facto de os dois cientistas estarem relacionados directamente com a Química terá, porventura, introduzido alguma subjectividade na análise.

Reportemo-nos agora ao Mapa de Consenso (Figura 5) proposto por Richard Klavans e Kevin Boyack, ambos cientistas computacionais dedicados à visualização. Das 16 áreas científicas propostas, é a Química que apresenta o mais elevado número de ligações de consenso, cinco, conjuntamente com a Engenharia, embora esta seja muito mais fraca; as Especialidades Médicas, a Bioquímica e a Física ostentam quatro. Note-se, ainda, que é na região que compreende a Química, a Química Física e a Física que se situa a maior rede de influências relativas.

É indiscutível a vantagem da utilização da cientometria. Os mapas de ciência constituem uma poderosa ferramenta de esquematização e de informação relacional inteligível. No entanto, a informação utilizada na sua concepção - a escolha dos indicadores bibliométricos e da metodologia adoptada, aliada à subjectividade do planeador - podem conduzir a resultados dissemelhantes. A posição e ligações da Matemática, por exemplo, têm sofrido sério debate e as Ciências Biomédicas surgem, por vezes, como pólo preferencial de interacção [12-14].

A importância da Química vale por si mesma - nós somos Química e tudo o que nos rodeia Química é... mas não será demais enfatizar a relevância do seu conhecimento para o surgimento e desenvolvimento de muitos outras áreas científicas. É necessário expulsar os fantasmas da dificuldade e do desinteresse com que a Química, a par com a Matemática e a Física, se encontra actualmente envolvida. O afastamento da Química dos currículos científicos é, como se viu, contranatura. A educação desta ciência passa, indubitavelmente, pela aprendizagem de um conjunto robusto dos seus tópicos fundamentais com a correspondente actualização; mas não exclusivamente. Em paralelo, é indispensável ensinar a metodologia científica, alimentando um pensamento curioso, crítico, integrado... e alegre. A incorporação de problemas do quotidiano, a superação da dicotomia teoria-prática, a articulação com outros saberes ou a apresentação “colorida” de case studies podem ser factores aliciantes num processo de aprendizagem $[15,16]$.

Os cientistas que têm protagonizado as maiores descobertas têm encarado a ciência como uma forma de cultura integrada. Querem compreender mais. Querem compreender melhor. Continuam a edificar a Torre das Ciências.

\section{REFERÊNCIAS}

[1] R. Verdenal, A Filosofia Positiva de Auguste Comte, in "A Filosofia e a História 1780-1880, História da Filosofia”, F. Châtelet (dir.), Publicações Dom Quixote, Lisboa, 1983

[2] R. Gonçalves-Maia, "Ciência, Pós-Ciência, Metaciência”,

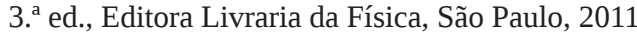

[3] J.D. Bernal, “The Social Function of Science”, Routledge \& Kegan Ltd, Londres, 1939

[4] K. Börner, "Atlas of Science - Visualizing What We Know”, The MIT Press, Cambridge, 2010

[5] A.T. Balaban, D.J. Klein, Scientometrics 69 (2006) 615637

[6] R. Klavans, K.W. Boyack, JASIST 60 (2009) 455-476

[7] A ideia de “consenso" como condição necessária para a acumulação de conhecimento, mesmo nas fronteiras da investigação, tinha sido defendida numa base sociológica por Stephen Cole [8].

[8] S. Cole, AJS 89 (1983) 111- 139

[9] A “Torre das Influências Felizes” ou Ling-Tai, diz a lenda, era o centro do paraíso terrestre na China e servia não só para observar os céus, mas também para deles receber influências positivas.

[10] N. Baron, "Escape from the Ivory Tower: A Guide to Making Your Science Matter”, Island Press, Nova Iorque, 2010

[11] T.E. Brown, H.E. LeMay Jr., B.E. Bursten, C.J. Murphy, P.M.Woodward, "Chemistry - The Central Science”, Prentice Hall, Boston, 1. ${ }^{\mathrm{a}}$ ed., 1977; 12. ${ }^{\text {a }}$ ed., 2012

[12] C. Reinhardt (ed.), "Chemical Sciences in the $20^{\text {th }}$ Century - Bridging Boundaries”, Wiley-VCH, Weinheim, 2001

[13] Scimago Group: F. Moya-Anegón, B. Vargas-Quesada, Z. Chinchilla-Rodríguez, E. Corera-Álvarez, F.J. MunozFernández, V. Herrero-Solana, JASIST 58 (2007) 2167$-2179$

[14] I. Rafols, A.L.Porter, L. Leydesdorff, JASIST 61 (2010) 1871-1887

[15] R. Gonçalves-Maia, Revue 6 (2006) 12-16

[16] R.M. Hazen, J. Trefil, “Science Matters - Achieving Scientific Literacy”, Anchor Books, Nova Iorque, 2. ${ }^{\text {a }}$ ed. 2009

Faça-se sócio da SPQ, receba o Boletim QUÍMICA e tenha acesso:

Às últimas notícias do mundo da Química - A artigos de relevo sobre a Química - A entrevistas com membros ilustres da Química - A uma agenda dos mais importantes eventos sobre Química aqui e além fronteiras. 